\title{
Development and Diagnostic Accuracy of the Screening of the Dimensional Clinical Personality Inventory
}

\author{
Lucas de Francisco Carvalho \\ Giselle Pianowski \\ Universidade São Francisco, SP, Brasil. \\ Universidade São Francisco, SP, Brasil. \\ Ana Maria Reis \\ Universidade São Francisco, SP, Brasil.
}

\begin{abstract}
The assessment of personality disorders assumes unquestioned clinical relevance when considering the prevalence rates in the general population. Tests assessing the typical pathological traits of these disorders has been adapted to and developed in Brazil. However, there is a gap in the country of screening tools for personality disorders. Screening tools are designed to allow a fast and informative application on the likelihood of a positive diagnosis, where the consequence should be conveyed to a diagnostic assessment. Using as a base the Dimensional Clinical Personality Inventory (IDCP), developed at the national level, the objective of this research was to develop a screening tool for personality disorders, as well as investigate its diagnostic accuracy. The study included 1,196 people, aging between 18 and 73 years $(M=26.32, S D=8.69)$, and $64.1 \%$ female. The sample was divided into clinical and non-clinical group. We used an empirical approach based on criteria for selection of items similar to those adopted in the development of Minnesota Multiphasic Personality Inventory was used (MMPI). The logistic regression analysis and also the calculation of Cohen's d indicated the items that best discriminate against people with personality disorders and those without this diagnosis. We achieved a final set of 15 items with satisfactory sensitivity and specificity for screening test. We discusses the strengths and limitations of screening version of the IDCP and guidelines for further study.
\end{abstract}

Keywords: Personality Disorder, Triage, Psychopathology Picture, Personality Measures, Diagnosis. 


\section{Desenvolvimento e Acurácia Diagnóstica do Inventário Dimensional Clínico da Personalidade - Versão Triagem}

Resumo: A avaliação dos transtornos da personalidade assume relevância clínica inquestionável ao se considerar os índices de prevalência na população geral. Testes avaliando os traços patológicos típicos desses transtornos vêm sendo adaptados e desenvolvidos no Brasil. Contudo, há no país uma lacuna quanto a ferramentas de triagem para transtornos da personalidade. Ferramentas de triagem visam possibilitar uma aplicação rápida e informativa sobre a probabilidade de um diagnóstico positivo, casos em que a consequência deve ser o encaminhamento para uma avaliação diagnóstica. Utilizando como base o Inventário Dimensional Clínico da Personalidade (IDCP), instrumento elaborado em âmbito nacional, o objetivo desta pesquisa foi desenvolver uma ferramenta de triagem para transtornos da personalidade, bem como investigar sua acurácia diagnóstica. Participaram do estudo 1.196 pessoas, com idade variando entre 18 e 73 anos $(\mathrm{M}=26,32 ; \mathrm{DP}=8,69)$, sendo $64,1 \%$ do sexo feminino. A amostra foi dividida em grupo clínico e não clínico. Foi utilizada uma abordagem empírica com base em critério para seleção dos itens, similar àquela adotada no desenvolvimento do Minnesota Multiphasic Personality Inventory (MMPI). As análises de regressão logística e também o cálculo do d de Cohen indicaram os itens que melhor discriminam pessoas com transtornos da personalidade e pessoas sem esse diagnóstico. Chegou-se a um conjunto final de 15 itens com sensibilidade e especificidade satisfatórios para um teste de triagem. Discute-se as forças e limitações da versão de triagem do IDCP e diretrizes para continuidade dos estudos.

Palavras-chave: Distúrbios da Personalidade, Triagem, Quadros Psicopatológicos, Medidas de Personalidade, Diagnóstico.

\section{Desarrollo y Precisión Diagnóstica del Inventario Dimensional Clínico de la Personalidad - Versión Clasificación}

Resumen: La evaluación de los trastornos dela personalidad asume relevancia clínica incuestionable cuando se consideran las tasas de prevalencia en la población general. Pruebas de evaluación de los rasgos patológicos típicos de estos trastornos han sido adaptadas y desarrolladas en Brasil. Sin embargo, en el país hay una carencia de herramientas de detección para los trastornos de la personalidad. Las herramientas de clasificación están diseñadas para permitir una aplicación rápida e informativa sobre la probabilidad de un diagnóstico positivo, donde la consecuencia debe ser transportada a una evaluación de diagnóstico. Utilizando como base el Inventario Dimensional Clínico de la Personalidad (IDCP), instrumento desarrollado en ámbito nacional, el objetivo de esta investigación fue desarrollar una herramienta de detección de trastornos de la personalidad, así como investigar su precisión diagnóstica. El estudio incluyó a 1.196 personas, con edad variando entre 18 y 73 años $(\mathrm{M}=26,32$, DP = 8,69), siendo el 64,1\% del sexo femenino. La muestra se dividió en grupo clínico y no clínico. Se utilizó un enfoque empírico basado en criterios para selección de elementos, similar a la adoptada en el desarrollo del Minnesota Multiphasic Personality Inventory (MMPI). Los análisis de regresión logística y también el cálculo del d de Cohen indicaron los elementos que mejor discriminan a las personas con trastornos de personalidad y a las personas que no tienen este diagnóstico. Hemos conseguido un conjunto final de 15 elementos con sensibilidad y especificidad satisfactorias para una prueba de clasificación. Se discuten las ventajas y limitaciones de la versión de clasificación del IDCP y las directrices para su posterior estudio.

Palabras clave: Trastornos de la personalidad, Clasificación, Cuadros Psicopatológicos, Medidas de Personalidad, Diagnóstico. 
Personality Disorders (PDs) are characterized as persistent and maladaptive patterns of thoughts, feelings, perceptions, and behaviors, deviant from the expectations of the sociocultural group of belonging (American Psychiatry Association, 2013; Millon, 2011). The evaluation and diagnosis take on an unquestionable clinical relevance when the prevalence of PDs identified in the general population (US) is from 5 to $10 \%$ (Samuels, 2011), with a mean of $13 \%$ in Western countries (Germans, Van Heck, \& Hodiamont, 2012), and even greater numbers in North and South America (Huang et al., 2006).

In general health systems, the prevalence of PDs in primary health care patients has risen between 20 and 30\% (Casey, \& Tyrer, 1990; Moran, Jenkins, Tylee, Blizard, \& Mann, 2000), and is linked to clinical diseases, difficulties in adhering to treatment, and worse prognoses (Gross et al., 2002; Lovato, 2011; Moran et al., 2000; 2003; Newton-Howes, Tyrer, \& Johnsen, 2006; Tyrer, Reed, \& Crawford, 2015), besides being commonly related to mortality (Samuels, 2011; Tyrer et al., 2015). The high index of diagnostic suspicion has led to referrals by the general medical clinic (Olssøn, Sørebø, \& Dahl, 2011), which is consistent with the frequent diagnosis of PDs in outpatient psychiatric clinics (Zimmerman, Chelminski, \& Young, 2008; Alnaes \& Torgersen, 1988), in outpatients (around 50\%; Beckwith, Moran, \& Reilly, 2014), and the frequent comorbidity of PDs with other psychiatric disorders, leading to an increased severity of the medical conditions (Hayward, \& Moran, 2008; Links, \& Eynan, 2013; Zimmerman, Rothschild, $\&$ Chelminski 2005), being also associated with risk of suicide (Cailhol et al. 2008; Lovato, 2011; Mergui, Raveh, Gropp, Golmard, \& Jaworowski, 2014; Rodriguez et al., 2016; Samuels, 2011).

Despite the high prevalence of PDs both in the outpatient medical and psychiatric clinics and the emphasis placed on the need for initiatives that minimize the impact of PDs in public health (Mergui et al., 2014; Samuels, 2011), data indicate that these conditions are underdiagnosed (Germans et al., 2012; Hengartner, 2015; Tyrer et al., 2015; Zimmerman et al., 2008). This is due to the greater familiarity of professionals with other psychiatric disorders rather than PDs and the limitations on the diagnosis of these conditions (Germans et al., 2012). The referral of patients to outpatient psychiatric clinics, for diagnosis, begins with the screening procedure (Alnaes, \& Torgersen, 1988; Zimmerman et al., 2008). The screening can be under- stood as a diagnostic step, a procedure aiming at identifying potential diagnostic conditions that need to be investigated. It consists on the first step in a diagnostic process, destined to the identification of pathology indicators that show the need for referral to a second stage, aimed at the diagnostic investigation and confirmation (Davies, \&Wilson, 2006; Germans et al., 2012).

In this context, the literature points out the lack of screening measures appropriate for institutional routines that are psychometrically efficient in identifying pathological manifestations, including those related to personality assessment (Alphen, Engelen, Kuin, Hoijtink, \& Derksen, 2006; Olssøn et al., 2011; Tyrer et al, 2015). Psychological screening measures for PDs aim to signal the existence of a PD with a reduced number of questions (questionnaires) or items (scales). Thus, the objective of such instruments, a priori, is not to determine the specific characteristics of the PDs, but to identify their presence.

The literature signals the better functioning of self-report measures to screen for PDs (e.g., Gárriz, \& Gutiérrez, 2009; Germans et al., 2012; Olssøn et al., 2011), identifying the psychometric adequacy of three instruments in this format: the Iowa Personality Disorder Screen (IPDS or IOWA), the Inventory of Interpersonal Problems - Personality Disorder scales - IIP-PD (Germans, et al., 2012; Morse, \& Pikonis, 2007), and the Standardized Assessment of Personality-Abbreviated Scale - SAPAS-SR (Germans et al., 2012). The literature also presents psychometric properties suitable for structured interviews in this context, such as the Standardized Assessment of Personality - SAP (Walters, Moran, Choudhury, Lee, \& Mann, 2004) and the Structured Clinical Interview for DSM-IV AXIS II Disorders - SCID-II (Germans et al., 2012). It is noteworthy that no studies of translation, cultural adaptation, or verification of the psychometric properties of these instruments were identified for the Brazilian population. Table 1 shows the diagnostic accuracy rates of the above tools.

Table 1 also shows a clear trend toward a higher sensitivity in relation to the sensitivity indices, except for two studies, one with the IPDS and another with the S-SCID-II. Furthermore, the highest sensitivity indices were for the IPDS in one of the studies, and for the SAPS-SR, in another study. Specificity was also higher for these two instruments, though in another study with the IPDS. 
Table 1

Diagnostic accuracy of the international PD screening tests.

\begin{tabular}{|c|c|c|c|c|c|}
\hline Papers & $\begin{array}{c}\text { Tests } \\
\text { (self-report) }\end{array}$ & SS (\%) & $\mathrm{SP}(\%)$ & $\mathrm{N}$ & $\mathrm{PD}(\%)$ \\
\hline Morse \& Pilkonis 2007 & IPDS (IOWA) & 78 & 44 & 81 & 44 \\
\hline Morse \& Pilkonis 2007 & IPDS (IOWA) & 80 & 55 & 70 & 84 \\
\hline Morse \& Pilkonis 2007 & IIP-PD & 67 & 56 & 81 & 44 \\
\hline \multirow[t]{2}{*}{ Walters et al. 2004} & SAP-AS & 78 & 50 & 57 & 64.9 \\
\hline & SAPAS [SAPAS-SR] & 83 & 80 & 195 & 50 \\
\hline \multirow[t]{2}{*}{ Germans et al. (2012) } & IPDS (IOWA) & 77 & 85 & 195 & 50 \\
\hline & S-SCID-II & 78 & 78 & 195 & 50 \\
\hline
\end{tabular}

From the psychometric perspective, the verification of the properties of a screening measure is supported by diagnostic accuracy designs (i.e., to verify the sensitivity and specificity of the measures). Diagnostic accuracy studies intend to describe the properties of a test with regard to the correct identification of true (sensitivity) and false (specificity) cases of the disease. Furthermore, it provides the calculation of the positive and negative likelihood ratio, value based on the sensitivity and specificity to indicate the probability that the disease is present or absent when the test is positive or negative, respectively (Parshall, 2013; Zhou, Obuchowski, \& McClish, 2002). Individuals correctly identified with the disorder are named as true-positive and those correctly identified without the disorder, true-negative. Similarly, healthy individuals incorrectly identified with the disorder are referred as false-positive and those individuals affected and not identified in the test are called false-negative.

Germans et al. (2012) point out the importance of analyzing and balancing the sensitivity and specificity indices in screening measures for PDs. The authors emphasize that high sensitivity values aim to ensure that a maximum number of true-positive people is identified, taking false-positives as not detrimental for this purpose. Specificity, in turn, must be achieved in a measure that discriminates true negatives, avoiding false negatives as much as possible. Thus, the literature indicates the adequacy of higher sensitivity values than those of specificity for these measures (Andreoli, Blay, \& Mari, 1998; Fletcher, Fletcher, \& Wagner, 1996; Klein, \& Costa, 1987; Morse, \& Pilkonis, 2007).

In short, it is desirable that screening measures, both for PDs and for the other psychiatric disorders, demonstrate adequate capacity to discriminate between positive and negative patients in relation to the disorder. Although the international reality indicates instruments as more and less suitable for the screening of PDs, in Brazil there is a shortage of evaluative tools for this purpose. That is, no PD screening tools presenting accuracy studies were found available for the Brazilian reality. Given this setting, the objective of this research was to develop a screening tool for PDs and to investigate its diagnostic accuracy. It is noteworthy that we started from an instrument for the assessment of pathological personality characteristics, existing and developed in Brazil, the Dimensional Clinical Personality Inventory (IDCP; Carvalho \& Primi, 2015).

\section{Method}

\section{Participants}

The study included 1,196 individuals, aged between 18 and 73 years $(\mathrm{M}=26.32$; $\mathrm{SD}=8.69)$, among which $64.1 \%(\mathrm{n}=767)$ were female, and $88.9 \%$ $(\mathrm{n}=1.063)$ were in higher education or were graduates. The sample was divided into clinical and nonclinical. The nonclinical group consisted of 1,093 participants, of which $62.8 \%(n=685)$ were women, aged between 18 and 59 years $(\mathrm{M}=24.96 ; \mathrm{SD}=6.85)$, attending higher education or graduated $(\mathrm{n}=1.030 ; 94.3 \%)$. As inclusion criteria for the nonclinical group, all reported not making use of psychotropic drugs or being under psychotherapy and/or psychiatric treatment.

The clinical group comprised 103 subjects from a public psychiatric hospital, diagnosed by psychiatrists or psychologists with clinical experience, using the Structured Clinical Interview for DSM-IV axis II (SCID-II), considered as the gold standard in diag- 
nostic accuracy studies (e.g., Germans et al., 2012). They were $78.1 \%$ female $(n=82)$, aged between 19 and 73 years $(\mathrm{M}=40.36$; $\mathrm{SD}=12.55)$, among which $40 \%(\mathrm{n}=42)$ reported having finished high school and $32.4 \%(\mathrm{n}=34)$ reported attending graduation or being graduated. In relation to the diagnosis, 52 were diagnosed with avoidant $\mathrm{PD}, 41$ with $\mathrm{PD}$ not otherwise specified (NOS), 31 with paranoid PD, 30 with borderline PD, 26 with obsessive-compulsive PD, 21 with dependent PD, 14 with histrionic PD, 11 with narcissistic PD, 8 with schizotypal PD, 5 with schizoid PD, and 3 with antisocial PD. The sum includes over 103 patients considering comorbidities.

\section{Instruments}

The Dimensional Clinic Personality Inventory is a self-report instrument, developed in 2011 by Carvalho and Primi, aimed at assessing pathological personality traits (Carvalho \& Primi, 2015). It consists of 163 items divided into 12 dimensions characterized by Dependency, Aggressiveness, Mood Instability, Eccentricity, Attention Seeking, Distrust, Grandiosity, Isolation, Criticism Avoidance, Self-sacrifice, Conscientiousness, and Impulsiveness. Through its application personality profiles are obtained based on these dimensions, so that high scores propose characteristics tending to a more pathological personality functioning. The psychometric properties of the instrument were verified by several studies (Carvalho, Oliveira Filho, Pessotto, \& Bortolotti, 2014; Carvalho \& Primi, 2015; 2016; Carvalho, Primi, \& Stone, 2014), which indicate favorable evidence of validity and acceptable reliability indices.

\section{Procedures}

The databases used in the study are from projects approved by Research Ethics Committees (CAAE: 0350.0.142.000-08 and CAAE: 21992113.1.0000.5514). For the nonclinical group, data were collected at universities in the countryside of the state of São Paulo, collectively in classrooms. In the case of the clinical group, data were collected in a public psychiatric hospital in the city of São Paulo, collectively in waiting rooms. The mean time for application in the nonclinical group was 25 minutes and for the clinical group, 40 minutes.

The final selection of items composing the IDCP screening version for personality disorders was based on a procedure similar to that adopted in the develop- ment of the Minnesota Multiphasic Personality Inventory (MMPI), considered an empirical approach based on criteria (Buchanan, 1994; Gregory, 2013). In this approach the relationship between items (i.e., internal structure) is less relevant compared to the ability of the set of items to discriminate groups. In this case, it was expected that the final set of items of the IDCP screening version would be able to discriminate people with personality disorders from those without these disorders.

Based on this approach, four sets of analyzes were conducted to establish the final set of items: logistic regression analysis with all forward (wald) items, initially excluding those presenting multicollinearity, verifying the weight and significance of each item in the discrimination between groups (clinical and nonclinical); logistic regression analysis, using the methods enter and forward (wald) only with the items that were kept between the IDCP and its revised version (IDCP-2); logistic regression analysis only with the items of the Mood Instability dimension; and standardized comparison (Cohen's $\mathrm{d}$ ) between groups at the level of items. It is noteworthy that for the first regression analysis, with all the items, only the forward method (wald) was used, since many predictor variables were inserted. The analysis covering only the 61 items kept between the IDCP and its revised version, IDCP-2, was performed considering that (a) the items kept in the revised version are empirically those which presented higher psychometric adequacy in previous studies (e.g., Carvalho \& Arruda, 2016; Carvalho, \& Pianowski, 2015; Carvalho, Pianowski, \& Miguel, 2015; Carvalho, \& Sette, 2015; , 2017; Carvalho, Sette, Capitão, \& Primi, 2014; Carvalho, Souza, \& Primi, 2014) and (b) despite some items shared with the analysis covering the IDCP in general, it is a different grouping of predictive variables. Similarly, in the third group of analyses, only the 27 items composing the Mood Instability dimension were used, since data presented in previous studies suggested this dimension as subjacent to pathological personality functioning in general (e.g., Abela, Carvalho, Cho, \& Yazigi, 2015; Carvalho, \& Primi, 2016;. Finally, for the fourth group analysis (i.e., Cohen's d) the percentile $75(\mathrm{~d}=0.60)$ was arbitrarily established as a cutoff for selecting the most discriminative items.

To determine the final set of items, we used as a criterion to keep only the items that were found in the final set of at least two of the four sets of tests per- 
formed, and a final logistic regression analysis was tested in this group. As a final procedure, we used the ROC Curve investigating the discriminative ability of the screening version of the IDCP via the sensitivity and specificity indices, as well as setting the ideal cutoff for discriminating the groups.

\section{Results}

\section{Logistic regression analysis with all items}

The first logistic regression analysis was performed using the forward method (wald), investigating the weight of each item for the prediction of groups. Although the method used kept only significant items at the end of the analysis, the model did not converge, probably due to the number of predictor variables. We used as a criterion to verify multicollinearity, in order to decrease the number of predictor variables. According to the observed data 16 items were excluded from the analysis. The $\mathbf{r}_{\text {cox \& snell }}^{2}$ adjusted was equal to $58.3 \%$ and the $\mathrm{r}^{2}$ nagelerke adjusted was equal to $85.9 \%$. In this case, $97.7 \%$ of the non-patients and $86.4 \%$ of patients were correctly identified, with a mean of $94.8 \%$. Table 2 presents the final set of items based on this analysis.

It is observed that in the final model 31 items of the initial 147 were kept after excluding some for multicollinearity, such as previously reported. It is worth noting that among the items kept, virtually all the dimensions of the IDCP were kept, except for two: Isolation and Conscientiousness. Furthermore, the most represented dimension was Mood Instability.

\section{Logistic regression with items kept between versions of the IDCP}

For the second regression analysis we selected only the 61 items kept between the IDCP and its version with the reformulated dimensions (IDCP-2), once these items underwent rigorous scrutiny in the reviews conducted, competed with new items formulated in these studies, and were still kept in the revised version of the instrument. Therefore, we applied both methods, enter and forward, selecting in the first case the items that presented significant $B$ and in the second case, the final model obtained.

In the analysis using the forward method, 14 items were kept, with $\mathrm{r}_{\text {cox \& snell }}^{2}$ adjusted at $35.5 \%$ and the $\mathrm{r}^{2}{ }_{\text {nagelkerke }}$ adjusted at $56.1 \%$; $96.3 \%$ of the non-patients
Table 2

Logistic regression analysis with IDCP all items.

\begin{tabular}{|c|c|c|c|c|}
\hline Dimensions & Items & $\mathrm{B}$ & Df & $\mathrm{P}$ \\
\hline MI/GRA & A009 & -0.89 & 1 & 0.01 \\
\hline MI & A010 & 1.65 & 1 & 0.00 \\
\hline IMP & A015 & -1.33 & 1 & 0.00 \\
\hline MI & A023 & 1.82 & 1 & 0.00 \\
\hline ECC & A031 & -1.67 & 1 & 0.00 \\
\hline ECC & A032 & 0.95 & 1 & 0.01 \\
\hline CA & A033 & 3.53 & 1 & 0.00 \\
\hline CA & A035 & -0.98 & 1 & 0.02 \\
\hline MI & A045 & 2.03 & 1 & 0.00 \\
\hline AGG/ATT & A053 & -1.80 & 1 & 0.00 \\
\hline GRA & A060 & 1.78 & 1 & 0.00 \\
\hline MI & A064 & 1.21 & 1 & 0.00 \\
\hline IMP & A066 & -1.06 & 1 & 0.00 \\
\hline ECC & A082 & -2.24 & 1 & 0.00 \\
\hline ATT & A089 & 2.30 & 1 & 0.00 \\
\hline ATT & A091 & -2.14 & 1 & 0.00 \\
\hline SS & A092 & 0.96 & 1 & 0.00 \\
\hline AGG & A105 & 1.85 & 1 & 0.00 \\
\hline GRA & B112 & -1.00 & 1 & 0.03 \\
\hline MI & B118 & $1 ., 37$ & 1 & 0.00 \\
\hline DEP & B119 & -1.79 & 1 & 0.00 \\
\hline ECC/DIS & B137 & 1.44 & 1 & 0.00 \\
\hline MI & B151 & -3.16 & 1 & 0.00 \\
\hline DIS & B157 & 0.75 & 1 & 0.03 \\
\hline ATT & B168 & -1.61 & 1 & 0.00 \\
\hline AGG & B175 & 1.54 & 1 & 0.00 \\
\hline AGG & B176 & 0.78 & 1 & 0.03 \\
\hline ECC & B188 & 0.92 & 1 & 0.01 \\
\hline ATT & B199 & -1.29 & 1 & 0.00 \\
\hline DIS & B211 & 0.90 & 1 & 0.00 \\
\hline \multirow[t]{2}{*}{ AGG } & B212 & -1.85 & 1 & 0.00 \\
\hline & Constant & -11.91 & 1 & 0.00 \\
\hline
\end{tabular}

Note. DEP = Dependency, AGG = Aggressiveness,

MI = Mood Instability, ECC $=$ Eccentricity,

AS = Attention Seeking, DIS = Distrust, GRA = Grandiosity, ISO = Isolation, $\mathrm{CA}=$ Criticism Avoidance, $\mathrm{SS}=$ Self-sacrifice, $\mathrm{CON}=$ Conscientiousness and IMP = Impulsiveness .

and $63.1 \%$ of patients were correctly identified, with a mean of $89.6 \%$. Using the enter method, 20 items were kept, the $\mathrm{r}_{\text {cox \& snell }}^{2}$ adjusted was of $40.7 \%$ and the $\mathrm{r}^{2}$ nagelkerke adjusted at $64.2 \%$, both higher than the previous method. Regarding accuracy, we verified $96.8 \%$ for non-patients and $68 \%$ for patients, with a mean of $91 \%$.

Unlike what was observed in regression analysis with all the items, Table 3 shows that the most prev- 
Table 3

Logistic regression analysis with items from IDCP-2.

\begin{tabular}{ccccc}
\hline \multirow{2}{*}{ Dimensions } & Items & Forward & Enter & Df \\
\cline { 3 - 4 } & & B & B & \\
\hline AGG & A018 & $0.45^{* * *}$ & 0.33 & 1 \\
ECC & A031 & -- & -0.41 & 1 \\
AGG & A067 & $-0.54^{* *}$ & -0.45 & 1 \\
AGG & B176 & $0.44^{* *}$ & $0.66^{* * *}$ & 1 \\
MI & B212 & $-1.12^{* * *}$ & $-1.31^{* * *}$ & 1 \\
MI & A064 & $0.65^{* * *}$ & $0.72^{* * *}$ & 1 \\
ECC & A028 & $0.45^{* *}$ & 0.24 & 1 \\
ECC & A032 & $0.43^{* * *}$ & $0.64^{* * *}$ & 1 \\
ECC & A082 & $-0.58^{* *}$ & $-0.88^{* * *}$ & 1 \\
ECC/DIS & B193 & $0.41^{* *}$ & $0.57^{* *}$ & 1 \\
ECC/ISO & A096 & $0.43^{* * *}$ & 0.27 & 1 \\
GRA & A069 & $-0.63^{* * *}$ & $-0.64^{* *}$ & 1 \\
MI/ISO & A099 & -- & $-0.54^{*}$ & 1 \\
GRA & B115 & -- & $0.72^{* *}$ & 1 \\
DEP/SS & B125 & -- & $-0.43^{*}$ & 1 \\
ECC/DIS & B137 & -- & $0.48^{*}$ & 1 \\
MI & B173 & -- & $0.59^{* *}$ & 1 \\
MI/ISO & B204 & $0.46^{* *}$ & $0.40^{*}$ & 1 \\
SS & A104 & $0.29^{*}$ & $0.39^{*}$ & 1 \\
DEP/SS & B131 & $0.49^{* * *}$ & 0.34 & 1 \\
& Constant & $-5.55^{* * *}$ & $-4.89^{* * *}$ & 1 \\
\hline
\end{tabular}

Note. ${ }^{*} \mathrm{p} \leq 0.10 ;{ }^{* *} \mathrm{p} \leq 0.05 ;{ }^{* * *} \mathrm{p} \leq 0.01 \mathrm{DEP}=$ Dependency, AGG $=$ Aggressiveness, $\mathrm{MI}=$ Mood Instability,

$\mathrm{ECC}=$ Eccentricity, AS = Attention Seeking, DIS = Distrust, GRA $=$ Grandiosity, ISO $=$ Isolation, $\mathrm{CA}=$ Criticism Avoidance, $\mathrm{SS}=$ Self-sacrifice, $\mathrm{CON}=$ Conscientiousness and IMP = Impulsiveness.

alent dimension was Eccentricity. Between the two methods used, nine items were repeated and excluding some repetition, 20 items were kept, considering also those that were kept in only one of the methods. For the final set, the items of dimensions Attention Seeking, Criticism Avoidance, Conscientiousness, and Impulsiveness were excluded.

\section{Logistical Regression with the items of the Mood Instability dimension}

In the third set of analyzes, logistic regression analysis was performed using the methods enter and forward only for the eight items of the Mood Instability dimension of the IDCP, based on previous data suggesting that this dimension is a general indicator of personality pathology. The same criteria of the second analytical group were used. In the analysis using the enter method, we obtained a $\mathrm{r}^{2}$ cox \& snell adjusted equal to $33.3 \%$ and $\mathrm{r}^{2}{ }_{\text {nagelkerke }}$ adjusted at $53 \%$, with accuracy of $95.6 \%$ for non-patients and $60 \%$ for patients, with a mean of $88.6 \%$; and for the forward method, the $\mathrm{r}^{2}{ }_{\text {cox }}$ $\&$ snell adjusted was of $30.6 \%$ and the $\mathrm{r}^{2}{ }_{\text {nagelkerke }}$ adjusted of $48.7 \%$, with $95.3 \%$ of non-patients and $56.2 \%$ of patients correctly identified, with a mean of $87.7 \%$. The data are presented in Table 4.

Based on Table 4 we can verify that all items of the Mood Instability dimension were significant according to the enter method, and only one item (A045) was not kept in the model using the forward method.

\section{Comparison between groups at the level of items}

As ultimately seeking to obtain the best set of items for the screening version of the IDCP, we used Cohen's d standardized measure as an indicator of the discriminative capacity of each of the 163 items of the IDCP. The $\mathrm{d}$ coefficients found ranged between zero and $1.22(\mathrm{M}=0.43 ; \mathrm{SD}=0.28)$. Given the obtained data, we arbitrarily adopted $\mathrm{d} \geq 0.60$ as a cutoff, since this value represented percentile 75 in the data observed. In this sense, we sought to select the items regarding the range of the $25 \%$ most discriminative among the 163 total items.

As a final product of the analysis and criteria used, we obtained a set of 37 items, of which seven presented a d higher than 1.0, 11 between 0.80 and 0.99 , and 19 items presented d between 0.60 and 0.79 . We emphasize that the Eccentricity dimension was the most prevalent in the final set of items in this analysis.

Table 4

Logistic regression analysis with Mood Instability items.

\begin{tabular}{cccc}
\hline \multirow{2}{*}{ Items } & Forward & Enter & \multirow{2}{*}{ Df } \\
\cline { 2 - 3 } & $\mathrm{B}$ & $\mathrm{B}$ & \\
\hline B170 & 0.50 & $0.47^{* *}$ & 1 \\
$\mathrm{~A} 075$ & 0.63 & $0.70^{* * *}$ & 1 \\
$\mathrm{~A} 045$ & -- & $0.44^{* *}$ & 1 \\
$\mathrm{~B} 151$ & -0.38 & $-0.39^{*}$ & 1 \\
$\mathrm{~A} 010$ & 0.30 & $0.44^{* * *}$ & 1 \\
$\mathrm{~A} 023$ & 0.87 & $0.96^{* * *}$ & 1 \\
$\mathrm{~A} 013$ & -0.42 & $-0.50^{* * *}$ & 1 \\
$\mathrm{~A} 064$ & 0.40 & $0.44^{* * *}$ & 1 \\
Constant & -6.22 & $-5.81^{* * *}$ & 1 \\
\hline Note ${ }^{*} \mathrm{p} \leq 0.10 * * * \mathrm{p}<0.05 * * * * \mathrm{p} \leq 0.01$ &
\end{tabular}




\section{Summary of the analyses and ROC curve}

After the completion of the four sets of analyzes, the end products of each set were added, seeking to arrive at a single set of items, based on the best items from each analytical set. For this purpose, belonging in the final product of at least two of the four groups analyzes was the criterion for keeping each item. From this we established a 21-item set.

Using the enter method, logistical regression was applied also to this group of items, resulting in $\mathrm{r}^{2}$ cox \& snell adjusted at $39.3 \%$ and $\mathrm{r}^{2}$ nagelerke adjusted at $62.7 \%$, with $96.1 \%$ of non-patients and $65.7 \%$ of patients correctly identified, and a mean of $90.2 \%$. However, five non-significant items (A018, A035, A045, B131 and B137) were identified in this set and, therefore, the analysis was performed again, excluding these items. The data obtained pointed to one in $\mathrm{r}^{2}$ cox \& snell adjusted a little lower than the previous, $38.7 \%$, and the same for the $\mathrm{r}^{2}$ nagelerke adjusted, $62.1 \%$, producing a correct identification of $95.7 \%$ for non-patients and of $65.7 \%$ for patients, with a mean equal to $89.9 \%$. Again the non-significant items were observed, and only one was found (A033), and once again the analysis of logistical regression was

Table 5

Logistic regression analysis for the 15 final items set.

\begin{tabular}{lccc}
\hline Dimensions & Items & B & df \\
\hline MI & A023 & $0.79^{* * *}$ & 1 \\
ECC & A031 & $-0.36^{*}$ & 1 \\
ECC & A032 & $0.40^{* *}$ & 1 \\
MI & A064 & $0.76^{* * *}$ & 1 \\
AGG & A067 & $-0.57^{* *}$ & 1 \\
SS & A069 & $-0.90^{* * *}$ & 1 \\
ECC & A082 & $-0.73^{* * *}$ & 1 \\
SS & A092 & $0.55^{* *}$ & 1 \\
GRA & A096 & $0.43^{* *}$ & 1 \\
MI & B118 & $0.46^{* * *}$ & 1 \\
AGG & B176 & $0.47^{* *}$ & 1 \\
ECC & B188 & $0.47^{* * *}$ & 1 \\
ECC/ISSO & B193 & $0.58^{* * *}$ & 1 \\
SS & B204 & $0.45^{* *}$ & 1 \\
AGG & B212 & $-1,37^{* * *}$ & 1 \\
& Constant & $-5,96^{* * *}$ & 1 \\
\hline
\end{tabular}

Note. ${ }^{*} \mathrm{p} \leq 0.10{ }^{* *} \mathrm{p} \leq 0.05 ;{ }^{* * *} \mathrm{p} \leq 0.01 \mathrm{DEP}=$ Dependency, AGG $=$ Aggressiveness, MI = Mood Instability,

ECC = Eccentricity, AS = Attention Seeking, DIS = Distrust, GRA = Grandiosity, ISO = Isolation, $\mathrm{CA}=$ Criticism

Avoidance, $\mathrm{SS}=$ Self-sacrifice, $\mathrm{CON}=$ Conscientiousness and IMP = Impulsiveness. used, excluding this item. The exclusion of the item resulted in practically no change in the data previously observed, being $\mathrm{r}^{2}{ }_{\text {cox \& snell }}$ adjusted $=38.5$ and $\mathrm{r}^{2}{ }_{\text {nagelkerke }}$ adjusted $=61.7 \%$, with $96.2 \%$ accuracy for non-patients and $62.9 \%$ for patients, with a mean of $89.8 \%$. The final set of 15 items is presented in Table 5 .

Most items presented a level of significance equal to or lower than 0.01 in the final model, and five items obtained negative loads on the model. In relation to the representativeness of the IDCP dimensions, the most recurrent was Eccentricity, followed by Mood Instability and Aggressiveness.

From thefinal set established, composed of 15 items, the ROC curve procedure was used in order to investigate the sensitivity and specificity indices of the items comprising the screening version of the IDCP. An area under the curve (AUC) equal to 0.90 was observed, suggesting good discriminative ability of the groups. The cutoff representing the ideal relation between sensitivity and specificity was equal to nine, which resulted in sensitivity equal to $89.5 \%$ and specificity of $67.2 \%$.

\section{Discussion}

Based on the psychometric adequacy of IDCP and IDCP-2, including discriminative ability of patients with PDs (IDCP; Carvalho, \& Primi, 2015; 2016; Carvalho, Primi, \& Stone, 2014; Carvalho, Oliveira Filho, Pessotto, \& Bortolotti, 2014; and IDCP-2; e.g., Carvalho, \& Arruda, 2016; Carvalho, \& Pianowski, 2015; Carvalho , Pianoswski, \& Miguel, 2015; Carvalho, \& Sette, 2015; 2017; Carvalho et al, 2014; Carvalho, Souza, \& Primi, 2014), this study focused on the development and verification of the diagnostic accuracy of a screening version of the IDCP, presenting satisfactory results that may meet the Brazilian gap of instruments available for an initial identification of individuals potentially diagnosed with PDs. Thus, based on a psychometric design that focuses more on the discriminative capacity and less on the internal structure of the set of items (Buchanan, 1994; Gregory, 2013), the data suggest diagnostic accuracy in the identification of patients with PDs for a set of 15 items primarily related to imbalances in interpersonal relationships, psychological distress experience, and self-neglect.

For this purpose, four groups of analysis were performed, focusing on identifying the potential of the items to predict PDs and to discriminate the clinical from the nonclinical group, using the empirical approach based on criterion (Buchanan, 1994; Greg- 
ory, 2007), which focuses on the discriminative ability of the set of items more than in its internal structure. The focus on the discriminative potential seems paramount when it comes to screen people with multiple personality dysfunctions, without the intention of differential diagnosis. Thus, we sought items that contributed to the prediction of people belonging to clinical groups, emphasizing the weight and significance of items in logistical regression analyses, and also which items showed greater difference in scores between the groups. It is noteworthy that partial analyzes were included (i.e., items from the original IDCP kept in the IDCP-2 and items that make up the Mood Instability dimension) in order to support these items in the final selection of the screening, given the quality of the items kept in the IDCP-2 (e.g., Carvalho, \& Arruda, 2016; Carvalho, \& Pianowski, 2015; Carvalho, Pianowski, \& Miguel, 2015; Carvalho, \& Sette, 2015; 2017; Carvalho, Sette, Capitão, \& Primi, 2014; Carvalho, Souza, \& Primi, 2014) and in the suitability of the content of Mood Instability in the identification of symptoms of PDs (e.g., Abela et al., 2015; Carvalho \& Primi, 2016).

The first group of analyses, using 147 items of the IDCP, pointed out a group of 31 items as more discriminative. It presented a high accuracy of $86.4 \%$, represented by almost all dimensions of the IDCP, except for the Isolation and Conscientiousness dimensions, highlighting the contribution of Mood Instability $\left(n_{\text {items }}=7\right)$ in the model. As a second analytical group, understanding the psychometric quality of the items of the original IDCP that were kept in the IDCP-2 after revision of the dimensions, we verified the discriminative ability of this specific set of items $\left(n_{\text {items }}=61\right)$ in the logistical regression, revealing a cluster of 20 items with a moderate accuracy (i.e., 63.1\%), primarily referring to characteristics of Eccentricity $\left(n_{\text {items }}=7\right)$ and Mood Instability $\left(n_{\text {items }}=5\right)$. As a third group of analyses, still based on logistic regressions, we focused on the Mood Instability dimension $\left(\mathrm{n}_{\text {items }}=27\right)$, that have been highly endorsed by people with different diagnoses of PDs (e.g., Abela et al., 2015; Carvalho \& Primi, 2016), and which highlighted a group of eight items with a moderate accuracy (i.e., $60 \%$ ) of clinical group.

The last analyses also sought to verify which items $\left(\mathrm{n}_{\text {items }}=163\right)$ presented greater discriminative ability between the clinical and nonclinical groups, yet based on the groups' means, i.e., items with greater discrepancies in the means were identified between groups. This comparison resulted in a set of 37 items that markedly distinguish the groups, encompassing particularly the Eccentricity and Dependency dimensions $\left(\mathrm{n}_{\mathrm{ittems}}=6\right)$, followed by Mood Instability and Criticism Avoidance ( $\left.\mathrm{n}_{\text {items }}=5\right)$ ), including also items in the dimension Isolation $\left(\mathrm{n}_{\mathrm{items}}=4\right)$, which was not observed in the first analyses.

It is noteworthy that the dimension Mood Instability, related to the characteristics of mood swings and high concern (Carvalho, \& Primi, 2015), was identified as one of the dimensions that most contributed in the first two regression analyses and remained presenting an expressive number of items that markedly distinguished the clinical from the nonclinical group (Cohen's d), still, showing a great potential for the identification of the clinical group (i.e., $60 \%$ ) when independent from other dimensions. These data confirm what has already been pointed out in the literature (e.g., Abela et al., 2015; Carvalho \& Primi, 2016). It is also noteworthy the contribution of Eccentricity, a dimension that involves interpersonal detachment, emotional inexpressiveness and characteristics of eccentric perception and behavior (Carvalho, \& Primi, 2015). The contribution of Eccentricity on discriminating people with various types of PDs was not expected, as it comprises characteristics that are more common to the schizotypal and schizoid PDs. These findings raise the hypothesis that the PDs in general entail social behavioral problems understood as eccentricity, and we suggest further investigations on the role of this dimension as a common component of the pathological personality manifestations in the different PDs.

In the selection of items kept in at least two of the four groups of analysis, as expected, the first set $(n=21)$ includes a significant amount of items derived from the dimensions Eccentricity $(n=6)$ and Mood Instability $(n=4)$. Next, the six items that were not contributing to the model were excluded, resulting in a final selection $(n=15)$ that maintained the same trend emphasizing the contribution of the characteristics of the dimensions Eccentricity $\left(n_{\text {items }}=5\right)$, with items focused on interpersonal detachment, eccentric style and paranormality; and Mood Instability $\left(\mathrm{n}_{\text {items }}=3\right.$ ), including items related to hopelessness and anxious concern. In addition, we observed the contribution of the dimensions Aggressiveness $\left(\mathrm{n}_{\mathrm{items}}=3\right)$, including items related to violent behavior and harassment, Self-sacrifice $\left(n_{\text {items }}=3\right)$, strictly with items related to the neglecting of one's own needs for the sake of meeting someone else's, and Grandiosity $\left(n_{\text {items }}=1\right)$, with an 
item referring to the feeling of being subject of lack of understanding and lack of recognition by others. The final set of items is in line with current proposals in the understanding of the PDs (APA, 2013; Krueger et al., 2011), including items regarding interpersonal losses, manifest by physically and morally aggressive behavior, interpersonal indifference and maladjustment, included in the items of the dimensions Eccentricity and Aggressiveness (Carvalho, \& Primi, 2015); and losses in the self, expressed by despondency, need for external support and neglecting of one's own needs, represented by the items of the Mood Instability and Self-sacrifice dimensions (Carvalho, \& Primi, 2015).

In practical terms, the screening version of the IDCP is a self-report instrument, with estimated application time of 15 minutes, variable according to the respondent's profile (e.g., psychiatric patients often take longer) and application (e.g., the application may be assisted, which will also require a longer time). The scale score ranges from 15 to 60 points, calculated as the sum of all items, but reversing the five items that presented negative loadings in the regression analysis. As a cutoff, two possible scores were established a priori (i.e., 9 and 10), both showing good values of sensitivity and specificity. However, a score equal to 9 was regarded as the most suitable for situations encompassing clinical patients versus non-clinical, like the present one, privileging the sensitivity, which is recommended for screening tools (Andreoli et al., 1998; Fletcher et al., 1996; Klein, \& Costa, 1987; Germans et al., 2012; Morse, \& Pilkonis, 2007). For situations focusing solely on community samples, maybe the cutoff of 10 would be most appropriate. Future studies must verify this hypothesis.

Considering the cutoff equal to nine, IDCP-screening showed a sensitivity index higher than those identified in international instruments (see Table 1), pointing to an ability to distinguish true positives $89.5 \%$ higher than the SAPAS, which presented the highest sensitivity index in the studies investigated (Germans et. al, 2012). Regarding specificity, the results showed that the IDCP-screening presents a $67.2 \%$ ability to identify true negatives, which is similar or higher than the international instruments, despite lower than the data obtained by Germans et. al (2012). We emphasize the preeminence of sensitivity in relation to specificity in screening instruments, since their purpose is to identify the maximum number of potential diagnostic, preferring to take on more cases of false positive than false negative (Andreoli et al., 1998; Fletcher et al.,
1996; Klein, \& Costa, 1987; Germans et al., 2012; Morse, \& Pilkonis, 2007), which reinforces the adequacy of the data found for the IDCP-screening.

Also regarding the data of diagnostic accuracy obtained using the IDCP-screening, we verified that the percentage of participants diagnosed with PD in the total sample $(9 \%)$ is lower than the percentage in the various international studies. However, two quantitative characteristics of the sample stand out: the percentage of participants with PD in the sample is within the prevalence expectations reported for the general population (i.e., 5 to 10\%; Samuels, 2011); and, in gross numbers, the total sample used in this study is significantly higher than that of other studies, including also a greater number of participants diagnosed with PD $(n=103)$. We did not find any data in the literature discussing changes in the probability of identifying cases in relation to the percentage in the sample, but it is reasonable to consider that with a greater number of cases in the sample, the screening could present a greater discriminative capacity. Future studies should seek to verify this question using the IDCP-screening. Also in relation to the sample characteristics, it should be noted that despite the small number of participants diagnosed with the schizotypal $(\mathrm{n}=8)$ and schizoid $(\mathrm{n}=5)$ PDs, reported in the literature as primarily related to eccentric characteristics (Abela et al., 2015), there was an unexpected high incidence of items of the Eccentricity dimension in the final selection of the IDCP-screening. We emphasize the need for future investigations on the role of the Eccentricity dimension in the diagnosis and understanding of the various personality disorders. Furthermore, it should be investigated if there are groups of PDs less detectable by the IDCP-screening compared to others, even though it has not been identified a pattern of positive cases undetected by the IDCP-screening in the present study.

\section{Final considerations}

Given the study's objective, we developed a screening version of the IDCP that appears to be clinically useful to screen for personality functioning potentially classified in the different personality disorders according to the DSM-5 (APA, 2013). Therefore, the IDCP-screening comprises 15 items related to the dimensions Eccentricity, Mood Instability, Aggressiveness, Self-sacrifice, and Grandiosity. Using the cutoff set at nine points, the IDCP-screening showed good sensitivity (84\% accuracy) to identify patients diagnosed with one or more PDs, and good specificity (77\% accuracy). In other words, it 
expressively discriminates people who do not present PDs, though allowing more cases of false-positive than false-negative, which is suitable to screening contexts.

This study presents limitations that should be considered given the data obtained, starting with the reduced number of patients, which, although higher than that used by the studies presented, represents only $9 \%$ of the sample used in this study. The design of this study, although appropriate, presents limitations, such as non-randomness in the search for patients and non-patients and the use of the gold standard only, and no other screening measure. Also, the nonclinical group was not assessed either, therefore people diag- nosed with personality disorders can fall on the group in which these diagnoses are not expected for the research. Further, we highlight that the screening version of IDCP is not composed by items from all dimensions, therefore future studies should verify if some PDs are less detectable than others. We also emphasize the need to verify the final set of the IDCP-screening in other groups, aiming specially to find correlation with other screening measures for PDs, in clinical and nonclinical groups. Furthermore, we also suggest studies that verify the role of Eccentricity and Mood Instability as relevant dimensions in the understanding and/or diagnosis of the different personality disorders.

\section{Referências}

AbelaR.K.,CarvalhoL.F.,ChoS.J.M.,\&YazigiL. (2015).Validityevidencesforthedimensionalclinicalpersonalityinventoryin outpatient psychiatric sample. Paidéia (Ribeirão Preto), 25(61), 221-28. https://doi.org/10.1590/1982-43272561201510

Alnaes, R., \& Torgersen, S. (1988). DSM-III symptom disorders (Axis I) and personality disorders (Axis II) in an outpatient population. Acta Psychiatrica Scandinavica, 78(3), 348-355. https://doi.org/10.1111/j.1600-0447.1988.tb06346.x

Alphen, S. P. J. V., Engelen, G. J. J. A., Kuin, Y., Hoijtink, H. J. A., \& Derksen, J. J. L. (2006). A preliminary study of the diagnostic accuracy of the Gerontological Personality disorders Scale (GPS). International Journal of Geriatric Psychiatry, 21(9), 862-868. https://doi.org/10.1002/gps.1572

American Psychiatry Association - APA. (2013). Diagnostic and statistical manual of mental disorders fifth edition (DSM-5). Washington, DC: American Psychiatry Association.

Andreoli, S. B., Blay, S. L., \& Mari, J. J. (1998). Escalas de rastreamento de psicopatologia. Revista de Psiquiatria Clínica, 25(5), 229-232.

Beckwith H., Moran P. F., \& Reilly J. (2014) Personality disorder prevalence in psychiatric outpatients: a systematic literature review. Personality and Mental Health, 8(2), 91-101. https://doi.org/10.1002/pmh.1252

Buchanan, R. D. (1994). The development of the Minnesota Multiphasic Personality Inventory. Journal of the History of the Behavioral Sciences, 30(2), 148-161. https://doi.org/10.1002/1520-6696(199404)30:2<148::AID-JHBS2300300204>3.0.CO;2-9

Cailhol, L., Damsa, C., Bui, E., Klein, R., Adam, E., Schmitt, L., \& Andreoli, A. (2008). Is assessing for borderline personality disorder useful in the referral after a suicide attempt? Encephale, 34(1), 23-30. https://doi.org/10.1016/j.encep.2007.04.004

Carvalho, L. F., \& Arruda, W. (2016). Revisão da dimensão isolamento do inventário dimensional clínico da personalidade. Temas em Psicologia, 24(1), 47-61. https://doi.org/10.9788/TP2016.1-04

Carvalho L. F., Oliveira Filho A. Q., Pessotto F., \& Bortolotti S. L. V. (2015) Application of the unfolding model to the aggression dimension of the Dimensional Clinical Personality Inventory (DCPI). Revista Colombiana de Psicologia, 23(2), 339-49. https://doi.org/10.15446/rcp.v23n2.41428

Carvalho L. F., \& Pianowski G. (2015). Revision of the Dependency dimension of the Dimensional Clinical Personality Inventory. Paidéia, 25(60), 57-65. https://doi.org/10.1590/1982-43272560201508

Carvalho L. F., Pianowski G., \& Miguel, F. K. (2015). Revision of the aggressiveness dimension of Dimensional Clinical Personality Inventory. Revista Psicologia-Teoria e Prática, 17(3), 146-163. https://doi.org/10.15348/1980-6906/psicologia.v17n3p146-163

Carvalho, L.F., \& Primi, R. (2015). Development and Internal Structure Investigation of the DimensionalClinical PersonalityInventory(IDCP). Psicologia:ReflexãoeCrítica, 28(2),322-330.https:// doi.org/10.1590/1678-7153.201528212

Carvalho, L. F., \& Primi, R (2016). Prototype matching of personality disorders with the Dimensional Clinical Personality Inventory. Psicologia: Teoria e Pesquisa, 32(2), 1-9. https://doi.org/10.1590/0102-3772e322214 
Carvalho L. F., Primi R., Stone G. E. (2014). Psychometric properties of the Inventário Dimensional Clínico da Personalidade (IDCP) using the Rating Scale Model. Avances em Psicología Latinoamericana, 32(3), 433-46. https://doi.org/10.12804/apl32.03.2014.09

Carvalho, L. F., \& Sette, C. P. (2015). Review and verification of the psychometric properties of the mood instability dimension of the Dimensional Clinical Personality Inventory. Acta Colombiana de Psicología, 18(2), 115-127. https://doi.org/10.14718/ACP.2015.18.2.10

Carvalho L. F., \& Sette C. P. (2017). Revision of the criticism avoidance dimension of the Dimensional Clinical Personality Inventory revision. Estudos de Psicologia (Campinas), 34(2), 219-231. https://doi.org/10.1590/198202752017000200004

Carvalho L. F., Sette C. P., Capitão C. G., \& Primi R. (2014). Psychometric properties of the revised attention seeking dimension of the inventário dimensional clínico da personalidade. Temas em Psicologia, 22(1), 147-60. https://doi.org/10.9788/TP2014.1-12

Carvalho, L. F., Souza B. D. B., \& Primi R. (2014). Psychometric properties of the revised conscientiousness dimension of Inventário Dimensional Clínico da Personalidade (IDCP). Trends in Psychiatry and Psychotherapy, 36(1), 23-31. https:// doi.org/10.1590/2237-6089-2013-0024

Casey, P. R., \& Tyrer, P. (1990). Personality disorder and psychiatric illness in general practice. British Journal of Psychiatry, 156(2), 261-5. https://doi.org/10.1192/bjp.156.2.261

Davies, G., \& Wilson, M. (2006). Pre-hospital care and triage in the UK. Surgery, 24(6), 190-193. https://doi.org/10.1383/surg.2006.24.6.190

Fletcher, R. H., Fletcher, S. W., \& Wagner, E. H. (1996). Epidemiologia clínica: elementos essenciais. Porto Alegre, RS: Artmed.

Gárriz, M., \& Gutiérrez, F. (2009). Personality disorder screenings: a meta-analysis. Actas Espanolas de Psiquiatria, 37(3), 148-152.

Germans, S., Van Heck, G., L., \& Hodiamont, P. P. G. (2012). Results of the search for personality disorder screening tools: clinical implications. Journal of Clinical Psychiatry, 73(2), 165-173. https://doi.org/10.4088/JCP.11m07067

Gregory, R. J. (2013). Psychological testing: history, principles, and applications (7th Ed.). Boston, MA: Pearson.

Gross, R., Olfson, M., Gameroff, M., Shea, S., Feder, A., Fuentes, M. et al. (2002). Borderline personality disorder in primary care. Archives of Internal Medicine, 162(1), 53-60. https://doi.org/10.1001/archinte.162.1.53

Hayward, M., \& Moran, P. (2008). Comorbidity of personality disorders and mental illnesses. Psychiatry, 7(3), 102-104. https://doi.org/10.1016/j.mppsy.2008.01.010

Hengartner, M. P. (2015). The detrimental impact of maladaptive personality on public mental health: a challenge for psychiatric practice. Frontiers in Psychiatry, 6, 87. https:// doi.org/10.3389/fpsyt.2015.00087

Huang, B., Grant, B. F., Dawson, D. A., Stinson, F. S., Chou, S. P., Saha, T. D. et al. (2006). Race-ethnicity and the prevalence and co-occurrence of Diagnostic and Statistical Manual of Mental Disorders, Fourth Edition, alcohol and drug use disorders and Axis I and II disorders: United States, 2001 to 2002. Comprehensive Psychiatry, 47(4), 252-257. https://doi.org/10.1016/j.comppsych.2005.11.001

Klein, C. H., Costa, E. A. (1987). Os erros de classificação e os resultados de estudos epidemiológicos. Cadernos de Saúde Pública, 3(3):35-46. https://doi.org/10.1590/S0102-311X1987000300003

Krueger, R. F., Eaton, N. R., Derringer, J., Markon, K. E., Watson, D., \& Skodol, A. E. (2011). Personality in DSM-5: Helping delineate personality disorder content and framing the metastructure. Journal of Personality Assessment, 93(4), 325-331. https://doi.org/10.1080/00223891.2011.577478

Links, P., \& Eynan, R. (2013). the relationship between personality disorders and Axis I psychopathology: deconstructing comorbidity. Review in Advance, 9, 529-554. https://doi.org/10.1146/annurev-clinpsy-050212-185624

Lovato, L. (2011). Transtornos da personalidade. Revista Brasileira de Psiquiatria, 33(3), 314-314. https://doi.org/10.1590/S1516-44462011000300020

Mergui, J., Raveh, D., Gropp, C., Golmard, J. L., \& Jaworowski, S. (2014). Prevalence and characteristics of cluster B personality disorder in a consultation-liaison psychiatry practice. International Journal of Psychiatry in Clinical Practice, 19(1), 65-70. https://doi.org/10.3109/13651501.2014.981543 
Millon T. (2011). Disorders of personality: introducing a DSM/ICD spectrum from normal to abnormal. New Jersey, NJ:Wiley.

Moran P., Jenkins R., Tylee A., Blizard R., \& Mann A. (2000). The prevalence of personality disorder among UK primary care attenders. Acta Psychiatrica Scandinavica, 102(1), 52-57. https://doi.org/10.1034/j. 1600-0447.2000.102001052.x

Moran, P., Walsh, E., Tyrer, P., Burns, T., Creed, F., \& Fahy, T. (2003). The impact of comorbid personality disorder on violence in psychosis- data from the UK700 trial. The British Journal of Psychiatry, 182(2), 129-134. https://doi.org/10.1192/bjp.182.2.129

Morse, J. Q., \& Pikonis, P. A. (2007). Screening for personality disorders. Journal of Personality Disorders, 21(2): 179-198. https://doi.org/10.1521/pedi.2007.21.2.179

Newton-Howes, G., Tyrer, P., \& Johnsen, T. (2006). Personality disorder and the outcome of depression: Meta-analyses of published studies. The British Journal of Psychiatry, 188(1), 13-20. https://doi.org/10.1192/bjp.188.1.13

Olssøn, I, Sørebø, O. \& Dahl, A. A. (2011). A cross-sectional testing of The Iowa Personality Disorder Screen in a psychiatric outpatient setting. BMC Psychiatry, 11: 105. https://doi.org/10.1186/1471-244X-11-105

Parshall, M. B. (2013). Unpacking the $2 \times 2$ table. Heart \& Lung: The Journal of Acute and Critical Care, 42(3), 221-226. https:// doi.org/10.1016/j.hrtlng.2013.01.006

Rodriguez, O. M. A. A. S., Fernández, J. L., Lora, C. H., León, S. O., González, M. H., Huerta, A. A. et al. (2016). Personality disorders and suicide attempts. European Psychiatry, 33(Suppl), S631. https://doi.org/10.1016/j. eurpsy.2016.01.1867

Samuels, J. (2011). Personality disorders: epidemiology and public health issues. International Review of Psychiatry, 23(3), 223-233. https://doi.org/10.3109/09540261.2011.588200

Tyrer P., Reed G. M., \& Crawford M. J. (2015) Classification, assessment, prevalence, and effect of personality disorder. Lancet, 385(9969), 717-726. https://doi.org/10.1016/S0140-6736(14)61995-4

Walters, P., Moran, P., Choudhury, P., Lee, T., \& Mann, A. (2004). Screening for personality disorder: a comparison of personality disorder assessment by patients and informants. International Journal of Methods in Psychiatric Research, 13(1), 34-39. https://doi.org/10.1002/mpr.162

Zhou, X. H., Obuchowski, N. A., \& McClish, D. K. (2002) Statistical methods in diagnostic medicine. New York, NY: Wiley.

Zimmerman, M., Chelminski, I., \& Young, D. (2008). The frequency of personality disorders in psychiatric patients. Psychiatric Clinics of North America, 31(3), 405-420. https://doi.org/10.1016/j.psc.2008.03.015

Zimmerman, M., Rothschild, L., \& Chelminski, I. (2005). The prevalence of DSM-IV personality disorders in psychiatric outpatients. American Journal of Psychiatry, 162(10), 1911-1918. https://doi.org/10.1176/appi.ajp.162.10.1911

\section{Lucas de Francisco Carvalho}

Professor do Programa de Pós-Graduação stricto sensu em Psicologia da Universidade São Francisco (USF), Bragança Paulista - SP. Brasil.

E-mail: lucas@labape.com.br

\section{Giselle Pianowski}

Professora do Programa de Pós-Graduação em Psicologia do Centro Universitário Fieo, Osasco - SP. Brasil.

E-mail: gisellepisnowski@gmail.com

\section{Ana Maria Reis}

Doutoranda do Programa de Pós-Graduação stricto sensu em Psicologia da Universidade São Francisco (USF), Bragança Paulista - SP. Brasil.

E-mail: anamariareisdasilva@yahoo.com.br 
Endereço para envio de correspondência:

R. Waldemar César da Silveira, 105

Jardim Cura D’Ars (SWIFT), Campinas - São Paulo

CEP 13045-510

Recebido 16/08/2016

Reformulado 21/09/2017

Aprovado 20/10/2017

Received 08/16/2016

Reformulated $09 / 21 / 2017$

Approved 10/20/2017

Recibido 16/08/2016

Reformulado 21/09/2017

Aceptado 20/10/2017

How to cite: Carvalho, L. F., Pianowski, G., \& Reis, A. M.Development and Diagnostic Accuracy of the Screening of the Dimensional Clinical Personality Inventory. Psicologia: Ciência e Profissão, 37(4), 1011-1024. https://doi.org/10.1590/1982-3703003082016

Como citar: Carvalho, L. F., Pianowski, G., \& Reis, A. M. Desenvolvimento e Acurácia Diagnóstica do Inventário Dimensional Clínico da Personalidade - Versão Triagem. Psicologia: Ciência e Profissão, 37(4), 1011-1024. https://doi.org/10.1590/1982 -3703003082016

Cómo citar: Carvalho, L. F., Pianowski, G., \& Reis, A. M. Desarrollo y Precisión Diagnóstica del Inventario Dimensional Clínico de la Personalidad - Versión Clasificación. Psicologia: Ciência e Profissão, 37(4), 1011-1024. https://doi.org/10.1590/1982-3703003082016 